\title{
Facile and Eco-Friendly Fabrication of Silver Nanoparticles Using Nyctanthes arbor-tristis Leaf Extract to Study Antibiofilm and Anticancer Properties against Candida albicans
}

\author{
Beema Shafreen Rajamohamed $\left(\mathbb{D},{ }^{1,2}\right.$ Seema Siddharthan $\left(\mathbb{D},{ }^{2}\right.$ Velmurugan Palanivel ${ }^{D},{ }^{3}$ \\ Mohanavel Vinayagam $\left(\mathbb{1},{ }^{3}\right.$ Vijayanand Selvaraj $\mathbb{1},{ }^{4}$ Sivakumar Subpiramaniyam $\mathbb{D}^{5},{ }^{5}$ \\ Saleh H. Salmen $\mathbb{1 0}^{6},{ }^{6}$ Sami Al Obaid, ${ }^{6}$ Sekar Palanivel, ${ }^{7}$ and Senthilkumar Subramanian ${ }^{8}{ }^{8}$ \\ ${ }^{1}$ Department of Biotechnology, Dr. Umayal Ramanathan College for Women, Algappapuram, Karaikudi 630003, India \\ ${ }^{2}$ Molecular and Nanomedicine Research Unit, Centre for Nanoscience and Nanotechnology (CNSNT), \\ Sathyabama Institute of Science and Technology, Chennai 600119, TN, India \\ ${ }^{3}$ Centre for Materials Engineering and Regenerative Medicine, Bharath Institute of Higher Education and Research, Selaiyur, \\ Chennai, Tamilnadu, India \\ ${ }^{4}$ Department of Biotechnology, Thiruvalluvar University, Serkadu, Tamilnadu, India \\ ${ }^{5}$ Department of Bioenvironmental Energy, College of Natural Resource and Life Science, Pusan National University, \\ Miryang 50463, Republic of Korea \\ ${ }^{6}$ Department of Botany and Microbiology, College of Science, King Saud University, P.O. Box 2455, Riyadh 11451, Saudi Arabia \\ ${ }^{7}$ Department of Zoology, Arignar Anna Government Arts College, Namakkal, Tamil Nadu, India \\ ${ }^{8}$ College of Medicine and Health Science, Jigjiga University, P.O. Box 1020, Jigjiga, Somali Region, Ethiopia
}

Correspondence should be addressed to Velmurugan Palanivel; palanivelmurugan2008@gmail.com and Senthilkumar Subramanian; senthilkumarsubramanian@jju.edu.et

Received 27 September 2021; Revised 7 December 2021; Accepted 14 December 2021; Published 7 January 2022

Academic Editor: Esmaeel Sharifi

Copyright (c) 2022 Beema Shafreen Rajamohamed et al. This is an open access article distributed under the Creative Commons Attribution License, which permits unrestricted use, distribution, and reproduction in any medium, provided the original work is properly cited.

The synthesis of silver nanoparticles has been gaining more attention in recent years due to their small size and high stability. For this study, silver nanoparticles were biosynthesized from leaf extract of the medicinal plant (N. arbor-tristis). Vitally, the shrub with tremendous medicinal usage was diversely observed in South Asia and South East Asia. The synthesized silver nanoparticles were characterized by color visualization, ultraviolet-visible spectrophotometry (UV-Vis), Fourier-transform infrared spectroscopy (FTIR), field emission-scanning electron microscopy (FESEM), energy-dispersive X-ray spectroscopy (EDX), and dynamic light scattering (DLS) technique. A sharp peak at $427 \mathrm{~nm}$ for biosynthesized nanoparticles was obtained using UV-Vis, which represents surface plasmon resonance. Thus, characterization techniques showed the green synthesis of AgNPs leads to the fabrication of spherical shape particles with a size of $67 \mathrm{~nm}$. Furthermore, AgNPs were subjected to antibiofilm studies against Candida albicans and it was observed that $0.5 \mu \mathrm{g} \mathrm{mL} \mathrm{L}^{-1}$ of AgNPs significantly reduced $50 \%$ of biofilm formation. These biosynthesized nanoparticles also showed a considerable reduction in viability of HeLa cells at $0.5 \mu \mathrm{g} \mathrm{mL} \mathrm{m}^{-1}$. The morphological changes induced by AgNPs were observed by AO/EB staining. The toxic effect of AgNPs was studied using brine shrimp as a model system. Therefore, it is envisaged that further investigation with these AgNPs can replace toxic chemicals, assist in the development of biomedical implants that can prevent biofilm formation, and avoid infections due to C. albicans. 


\section{Introduction}

Candida albicans is part of the common microflora in humans, and any slight alteration in the environment or immune suppression leads to the transition from commensal into pathogen [1]. C. albicans is an opportunistic fungal pathogen that can establish infection in almost all the organs of the human body. The pathogenesis of C. albicans is due to the production of several virulence factors; among them, biofilm formation plays an important role during infection [2]. C. albicans forms biofilm on indwelling devices and catheters that are in contact with host tissues. Thus, C. albicans complicates the therapy by penetrating deep into the tissues, virtually spreading to other superficial sites, and establishing the infection [3]. C. albicans is reported to be the one among the species of Candida that can result in indwelling material mediated bloodstream infections [4]. C. albicans biofilm has shown resistance to antifungal drugs such as echinocandins that are currently used for the treatment of invasive infection [5]. However, the development of new antifungal drugs is an escalating problem due to the antifungal resistance, toxicity, and paucity in the selection of the targets. Together, all these factors are responsible for clinical failure and lead to mortality in patients with invasive disease. Therefore, there is a need to identify new antibiofilm agents against C. albicans mediated infection [6].

Nanoparticles studies have remarkable recognition worldwide because of their size, shape, and surface morphology, which can play exclusive implications on controlling the physiochemical and biological properties of nanoparticles [7, 8]. Thus, nanoparticles application as nanomaterials has grown tremendously in different fields of biological science and medicine and has paved a way to design new devices and technocommercial products [9]. The synthesis of nanoparticles using a greener approach is gaining an advantage over the other methods since they are eco-friendly and prevent biological and environmental issues [10]. Biosynthesis of nanoparticles from medicinal plants has gained importance because they are easily available and extensively prescribed and practiced for the treatment of several diseases [11-13]. Plants are the major source of secondary metabolites, which has several biological activities. Different parts of the plants were used for synthesis of nanoparticles. Flavonoids, nonflavonoids, phenolic chemicals, lipids, and glycosides are occasionally found in plants. Thus, usage of plant materials for biosynthesis of metal particles can improve the efficacy of the biological activity. Leaves being a major source of the plants biological process were explored vastly for nanoparticle synthesis. The leaves of Lotus lalambensis and AgNPs synthesized have shown protective effect against oral candidiasis [14]. The synthesis of AgNPs from leaf extracts of Semecarpus anacardium, Glochidion lanceolarium, and Bridelia retusa has shown antibacterial and antibiofilm activity against human pathogens. Nyctanthes arbor-tristis belongs to the group of medicinal shrubs with a common name "night Jasmine" or represented as 'Pavalamalli' in Tamil. This shrub is very famous for its medicinal property and is dynamically used in most Asian countries for various ailments in mankind [15].
Almost every part of this shrub is used for treatment; for example, the leaf juice is used as purgative and to deworm infants and children. Leaves of $N$. arbor are used for treating high fever, rheumatism, and liver disorders. The bark of the shrub is used as antivenom. Besides, this shrub was also studied for its antibacterial, antifungal, antiviral, antiallergic, antihistaminic, anticancer, immunotoxic, and ulcerogenic properties [16-19]. Recently, Betulinic acid from the leaves of $N$. arbor was reported for having in vitro anticancer property [20]. Crude herbal plant extracts have been used to cure a variety of conditions since ancient times, including osteoarthritis, ulcers, cancer, heart disease, bone fractures, and diabetes. Extracts with antioxidative, antibacterial, and anti-inflammatory properties, in particular, might help to avoid difficulties and delays in tissue repair and regeneration [21].

Hence, in the current study, silver nanoparticles (AgNPs) from N. arbor-tristis leaf extract were synthesized and investigated against C. albicans biofilm. Consider using Nyctanthes arbor-tristis leaf extract to cure a variety of diseases as an effective and safe alternative to chemical medications that have no side effects [22].

\section{Experimental}

2.1. Preparation of the Plant Extract. Leaves of the medicinal plant N. arbor-tristis were collected from Karaikudi, Tamil $\mathrm{Nadu}$, India. The collected leaves were rinsed twice with deionized water to remove any dust particles and dried at room temperature (RT). Then, dried-out leaves were prepared as fine particles using a mixer grinder. About $10 \mathrm{~g}$ of the fine powder was added to $250 \mathrm{~mL}$ of deionized water and boiled for $30 \mathrm{~min}$ and left at RT. After complete cooling, extract was filtered using ordinary filter paper and stored in a vial at RT for further use.

2.2. Green Synthesis of Silver Nanoparticles. For the synthesis of sliver nanoparticles (AgNPs), $90 \mathrm{~mL}$ of silver nitrate (HiMedia, Mumbai, India) $\left(\mathrm{AgNO}_{3} 1 \mathrm{mM}\right)$ solution was mixed (added as drop) with $10 \mathrm{ml}$ of the plant extract taken in a $250 \mathrm{ml}$ conical flask. The reaction mixture was kept in continuous shaking conditions until the color of the extract changes. The changes in the reaction color within 15 minutes were recorded. The deep brown color of the solution without any further change will indicate that the silver ions have been reduced completely by the extract.

2.3. Characterization of AgNPs. The rapid synthesis of silver nanoparticles was characterized using UV-Vis spectroscopy (Cary-60, Agilent, USA). The spectra of the sample and control were recorded periodically for a wavelength range of $300 \mathrm{~nm}-600 \mathrm{~nm}$ at $2 \mathrm{~nm}$ resolution. The aqueous silver nanoparticles solution was dried and stored at $4^{\circ} \mathrm{C}$ for further study. The functional group of AgNPs was obtained using Fourier-Transform Infrared Spectroscopy (FTIR) (PerkinElmer Spectrum-One, USA) with a resolution of $2 \mathrm{~cm}^{-1}$ at a diffuse reflectance mode. The characteristics features of AgNPs such as morphology and size were studied 
using field emission-scanning microscopy (FESEM) with EDAX (Supra-55, Carl Zeiss, Germany) at an accelerating voltage of $20.00 \mathrm{kV}$.

2.4. Culture Preparation. C. albicans (ATCC: 90028) were maintained in Sabouraud Dextrose Agar (SDA). Before all the assays, the overnight culture was harvested by centrifugation (10,000 rpm, $5 \mathrm{~min}$ ). The supernatant was discarded followed by the suspension of the pellet with Sabouraud Dextrose Broth (SDB), containing $10^{6}$ cells $\mathrm{mL}^{-1}$ in the suspension, and used for further assay.

2.5. Biofilm Inhibition Assay. The formation of biofilm was allowed in polystyrene microtiter plates (24-well) for $48 \mathrm{~h}$ followed by removal of media from the well and washing gently with Phosphate buffer saline (PBS) to remove the planktonic cells. The wells in the microtiter plates were stained with crystal violet stain $(0.4 \%)$ to determine the biofilm inhibitory effect of AgNPs using a spectrophotometer at $570 \mathrm{~nm}$ [19].

2.6. Light and FESEM. The biofilm morphological changes were studied using different microscopic techniques. C. albicans cells grown on a glass slide $(1 \times 1 \mathrm{~cm})$ were kept inside 12 -well microtiter plates and incubated for $48 \mathrm{~h}$ at $37^{\circ} \mathrm{C}$. A test well was supplemented with AgNPs and the well without AgNPs was referred to as the control. The control and treated glass slides were washed with PBS and stained with crystal violet $(0.4 \%)$ for $5 \mathrm{~min}$. Later, the slides were destained, dried, and observed under a light microscope (Lieca, DM2000LED) at $400 \times$ magnification. For FESEM analysis, experimental slides were removed from the microtiter plates after incubation and washed with PBS and immersed into $2 \%$ glutaraldehyde solution for about $3 \mathrm{~h}$. Immediately, the slides were with PBS and fixed with series of ethanol 25\%, 50\%, and finally $100 \%$ and left for air drying. The slides were then sputtered with gold and examined under FESEM (Hitachi S-3000H, Japan).

2.7. Cell Culture Preparation and Condition. For the present study, the HeLa cervical cancer cell line was obtained from NCCS (National Centre for Cell Sciences), Pune, India. Eagle's minimum essential medium was added with $10 \%$ fetal bovine serum (HiMedia) and $20 \mu \mathrm{g} / \mathrm{ml}$ gentamicin to culture the HeLa cells. The cells were maintained under $97 \%$ humidity in a biological incubator at $37^{\circ} \mathrm{C}$ with $5 \% \mathrm{CO}_{2}$ and monitored routinely. Cells after reaching $80 \%$ confluence were used for other experiments.

2.8. Cytotoxicity Studies Using HeLa Cells. Through colorimetric reduction assay, the cytotoxic effect of the biosynthesized AgNPs against HeLa cells was measured. The soluble MTT will be metabolized by the mitochondrial enzymes of the viable HeLa cells into an insoluble colored tetrazolium salt [23]. Before the experiments, the HeLa cells $\left(10^{5}\right.$ cells $\left.\mathrm{mL}^{-1}\right)$ were dispensed into wells of the 96 - well plates and kept under incubation for $24 \mathrm{~h}$ at $37^{\circ} \mathrm{C}$. Test wells were added with HeLa cells and different concentrations of AgNPs $\left(0.25 \mu \mathrm{g}, 0.5 \mu \mathrm{g}\right.$, and $\left.1 \mu \mathrm{g} / \mathrm{mL}^{-1}\right)$. The plates were incubated $\left(5 \%\right.$ of $\mathrm{CO}_{2}$ at $\left.37^{\circ} \mathrm{C}\right)$ again for $24 \mathrm{~h}$. To evaluate the cell survival in the presence of AgNPs, $10 \mu \mathrm{L}$ of MTT solution (10 $\mathrm{mg} \mathrm{mL}^{-1}$ in PBS) was added to control and test wells and the plates were kept in dark condition at RT for about $4 \mathrm{~h}$. Finally, $100 \mu \mathrm{L}$ of DMSO was added to each well replacing the media from each well. The absorbance $\left(\mathrm{OD}_{570} \mathrm{~nm}\right)$ was determined with a microtiter plate reader and values were recorded (PerkinElmer, EnSpire, USA).

2.9. Acridine Orange/Ethidium Bromide (AO/EB) Staining. $\mathrm{AO} / \mathrm{EB}$ staining techniques were used to study the morphological changes in the HeLa cells in the presence and absence of AgNPs $\left(0.5 \mu \mathrm{g} / \mathrm{mL}^{-1}\right)$ [24]. Control and treated setup of HeLa cells were prepared as mentioned above. HeLa cells were stained with a final concentration of $100 \mu \mathrm{g} \mathrm{mL}^{-1}$ of AO/EB stain and the plates were left as such for $5 \mathrm{~min}$ at RT. HeLa cells were washed with deionized water twice and visualized under a fluorescence microscope (EVOS-fl digital).

2.10. Toxicity Assay Using Brine Shrimp. For studying the toxic effect of AgNPs, $4 \mathrm{~g}$ of cysts was mixed with $200 \mathrm{~mL}$ of seawater and kept at $30^{\circ} \mathrm{C}$ for $48 \mathrm{~h}$ light conditions. After $48 \mathrm{~h}$, the cyst hatched into the Artemia stage which was used for further studies. For this experiment, into each well of the 12-well microtiter plates, $2 \mathrm{~mL}$ of sterilized seawater was added and later 10 Artemias were transferred into each well. The infection wells containing Artemia were coincubated with $10^{6}$ cells $\mathrm{mL}^{-1}$ of $C$. albicans. Test wells containing $C$. albicans coincubated with Artemia were supplemented with AgNPs. Artemia with seawater alone was considered as a control well. The rate of survival of Artemia in the presence and absence of AgNPs was recorded for $24-48 \mathrm{~h}$ at $30^{\circ} \mathrm{C}$.

2.11. Statistical Analysis. Biological triplicates were conducted for all experiments and the results were shown in bar diagrams as the representation of standard deviation. The data were statistically compared and the difference was significantly defined using one-way ANOVA with $P<0.05$ recorded as significant.

\section{Results}

3.1. Characterization of AgNPs. The synthesis of AgNPs from plant extract was confirmed visually with color change in $15 \mathrm{~min}$ from greenish-brown to dark-brown color (Figure 1(a)). From the UV-Vis spectroscopy, a strong spectroscopic resonance peak was observed at $427 \mathrm{~nm}$, which is the signature peak of AgNPs (Figure 1(b)) that represents the fabrication of AgNPs. The functional groups of biosynthesized AgNPs were also analyzed using FTIR (Figure 1(c)). FTIR spectrum of AgNPs showed major 


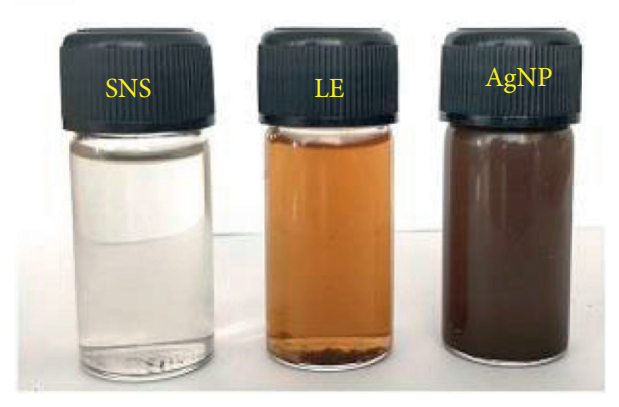

(a)

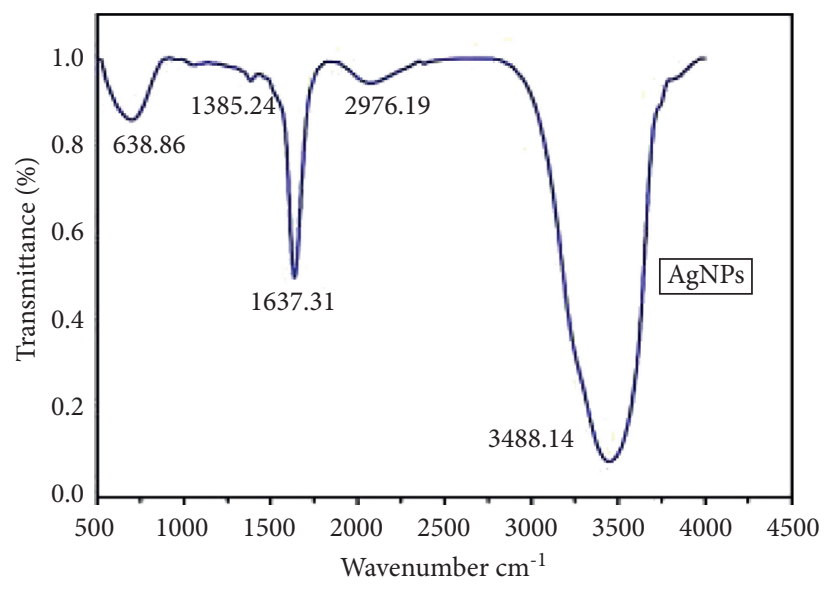

(c)

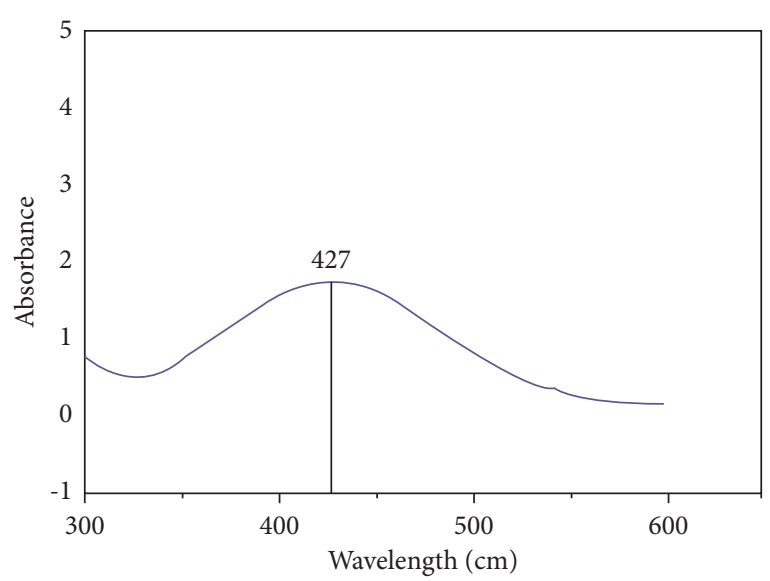

(b)

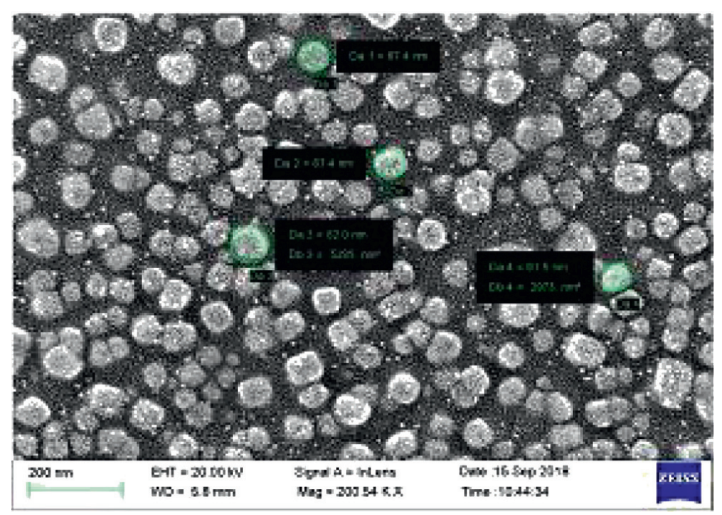

(d)

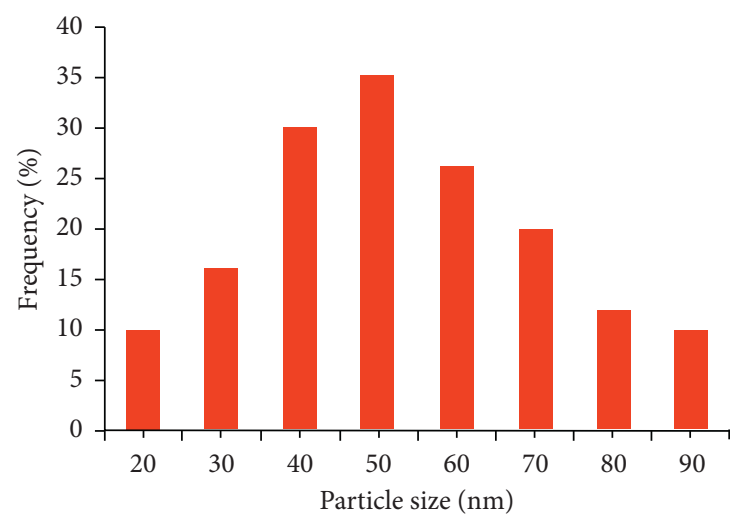

(e)

FIgURE 1: Biosynthesis and characterization of silver nanoparticles (AgNPs) by using the leaf extract of N. arbor-tristis. (a) The color change during AgNPs synthesis (silver nitrate solution: SNS, leaf extract: LE, silver nanoparticles: AgNPs). (b) UV-Vis spectrum shows the surface plasmon resonance reduction by leaf extract at $427 \mathrm{~nm}$ due to silver nanoparticles synthesis. (c) FTIR spectrum of AgNPs synthesis. (d) SEM micrograph of silver nanoparticles showing spherical morphology. (e) Particle size distribution histograms of AgNPs.

absorption peak at $698 \mathrm{~cm}^{-1}, 1385 \mathrm{~cm}^{-1}, 1637.31 \mathrm{~cm}^{-1}$, $2075.10 \mathrm{~cm}^{-1}$, and $3488.14 \mathrm{~cm}^{-1}$. The peak represents the stretching vibrations of $\mathrm{C}-\mathrm{H}$ bend $\left(698 \mathrm{~cm}^{-1}\right), \quad \mathrm{C}-\mathrm{F}$ $\left(1385 \mathrm{~cm}^{-1}\right), \mathrm{C}=\mathrm{C}$ stretch $\left(1637 \mathrm{~cm}^{-1}\right)$, and $\mathrm{O}-\mathrm{H}$ intramolecular hydrogen bonds $\left(3488.14 \mathrm{~cm}^{-1}\right)$. The broad signal at $3488.14 \mathrm{~cm}^{-1}$ may also correspond to stretching of the $\mathrm{O}-\mathrm{H}$ or the $\mathrm{H}$-bonds present in the polyphenolic group, polysaccharides, or from the amino acids. The signal at $1637 \mathrm{~cm}^{-1}$ represents the stretching of the $(\mathrm{NH})=\mathrm{O}$ group in either of the macromolecules [25]. From FESEM, the 
morphology and size of AgNPs were determined and with the average size of $67 \mathrm{~nm}$ and spherical shape (Figure 1(d)) and particle size distribution were revealed in Figure 1(e). Further, the elemental silver in the biosynthesized AgNPs was examined using EDX analysis and a peak at $3 \mathrm{KeV}$ represents the silver ions as the main component, indicating the fabrication of $N$. arbor-tristis leaf extract into AgNPs (Supplementary Figure S1).

3.2. Antibiofilm Effect of AgNPs against C. albicans Biofilm. Antibiofilm activity of AgNPs was determined using crystal violet assay, which showed a progressive inhibition of biofilm formed by C. albicans. AgNPs at $1 \mu \mathrm{g} \mathrm{mL}^{-1}$ concentration showed $81 \%$ of biofilm inhibition as shown in (Figure 2). However, AgNPs at $0.5 \mu \mathrm{g} \mathrm{mL}^{-1}$ concentration showing $50 \%$ biofilm inhibition were determined to be biofilm inhibitory concentrations (BIC). From light microscopic images, it was observed that the C. albicans formed a structured arrangement of yeast cells in the biofilm (Figure 3(a)). Figures 3(b)-3(d) represent that in the presence of AgNPs there is a sequential reduction in the adhesion of $C$. albicans to the matrix. From the SEM image, it was confirmed that C. albicans forms a structured biofilm embedded with exopolysaccharides (Figure 4(a)). In treatment with AgNPs, there was no exopolysaccharide and only scant cells were seen to be adhering to the matrix (Figure 4(b)).

3.3. Cytotoxicity Studies Using HeLa Cells. The $\mathrm{IC}_{50}$ value for the HeLa cells was determined as $0.393 \mu \mathrm{g} \mathrm{mL}^{-1}$. Morphological changes due to AgNPs were visualized using $\mathrm{AO} / \mathrm{EB}$ under the fluorescence microscope. Figure 5(a) represents the control group of HeLa cells with green fluorescence due to the intact nuclei with clear cell boundaries. HeLa cells treated with AgNPs showed a fluorescence color of yellowgreen which corresponds to the early apoptotic nucleus. The orange-red fluorescence represents the necrotic cells with uneven shapes. Thus, from AO/EB staining, the apoptotic characteristics of HeLa cells due to the treatment of AgNPs were revealed. Cytotoxic effect of AgNPs at different concentrations $\left(0.25,0.5\right.$, and $\left.1 \mu \mathrm{g} \mathrm{mL}^{-1}\right)$ was determined against HeLa cells using MTT assay. In the presence of AgNPs, the survival rate of HeLa cells was $62 \%, 45 \%$, and $28 \%$, respectively (Figure $5(\mathrm{~b})$ ).

3.4. Toxicity Assay Using Brine Shrimp. The in vivo effect of $\operatorname{AgNPs}\left(0.5 \mu \mathrm{g} \mathrm{mL}^{-1}\right)$ on C. albicans-infected brine shrimp at their nauplii stage was tested. Nauplii infected with C. albicans showed $45 \%$ survival at $24 \mathrm{~h}$ and $30 \%$ survival at $48 \mathrm{~h}$. In the presence of AgNPs, the survival rate of nauplii infected with C. albicans showed $80 \%$ survival at $24 \mathrm{~h}$ and $75 \%$ survival at $48 \mathrm{~h}$ (Figure 6). However, there were $100 \%$ survival nauplii in the presence of AgNPs $\left(0.5 \mu \mathrm{g} \mathrm{mL}^{-1}\right)$ which is a comprehensive evidence that AgNPs are not toxic for the nauplii.

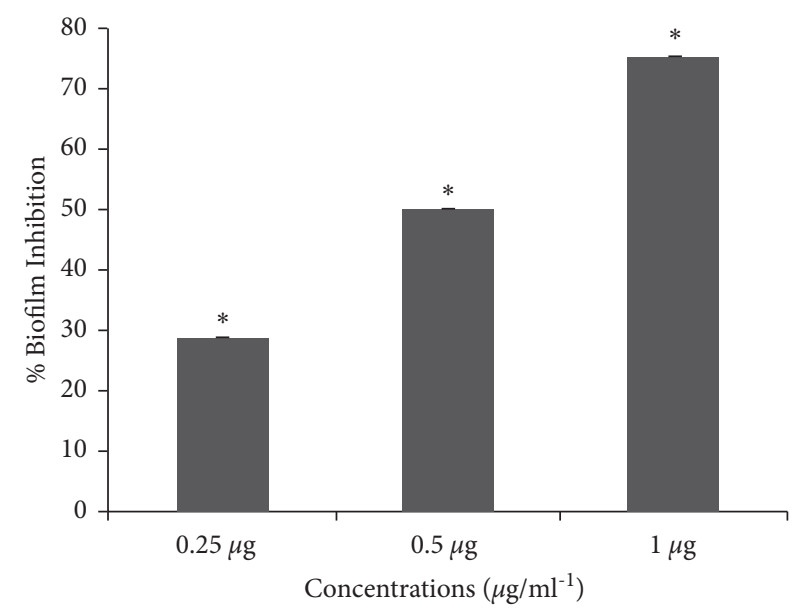

Figure 2: Antibiofilm activity of AgNPs against C. albicans biofilm at different concentrations. A biofilm inhibitory concentration (BIC) of AgNPs was determined as $0.5 \mu \mathrm{g} \mathrm{mL}^{-1}$ showing the maximum inhibition of $50 \% .{ }^{*} P<0.05$ statistical significance was calculated using one-way ANOVA.

\section{Discussion}

Green synthesis of nanoparticles is considered to be ecofriendly [26] comparing with other materials such as microorganisms which are laborious and time-consuming. In green synthesis, any part of the plant materials is used and their extracts are used as a capping agent to fabricate the materials. In this study, the leaf extracts of N. arbor-tristis, a well-known medicinal plant, were used for biosynthesis of silver nanoparticles. The biosynthesis of AgNPs was observed within $15 \mathrm{~min}$ with a change in color from green to dark-brown color with an average size of $67 \mathrm{~nm}$ having a spherical shape. Most of the reports with AgNPs synthesized from plant extracts show the color change from yellow to brown with a plasma resonance peak appearing in a region of $406-453 \mathrm{~nm}$ which demonstrates the fabrication process $[27,28]$. The leaf extract used in the study has a dual role, which can reduce as well as cap the AgNPs, which was confirmed using the FTIR technique. The AgNPs were further investigated for biofilm inhibition and sequential reduction was observed.

However, $0.5 \mu \mathrm{g} / \mathrm{mL}$ showing $50 \%$ biofilm inhibition was determined as BIC and further experimented. To purge mature C. albicans biofilm is very difficult due to host defense mechanisms and antimicrobial resistance. In addition, C. albicans entering the phenotypic state change from yeast to hyphal transition in a biofilm are more complicated to be treated. Therefore, it is always easier and beneficial to eradicate the initial stages of biofilm [29-31]. Microscopic images (light and SEM) substantiate that AgNPs prevent the attachment of yeast cells to a glass slide. Hence, AgNPs exclude C. albicans biofilm formation and therefore it is envisaged that AgNPs could facilitate the eradication of biofilm that is difficult during treatment with antibiotics. C. albicans undergoes morphological switching from yeast cells to hyphal forms, which is very important for adherence and biofilm formation. Indeed, this step is very essential for 

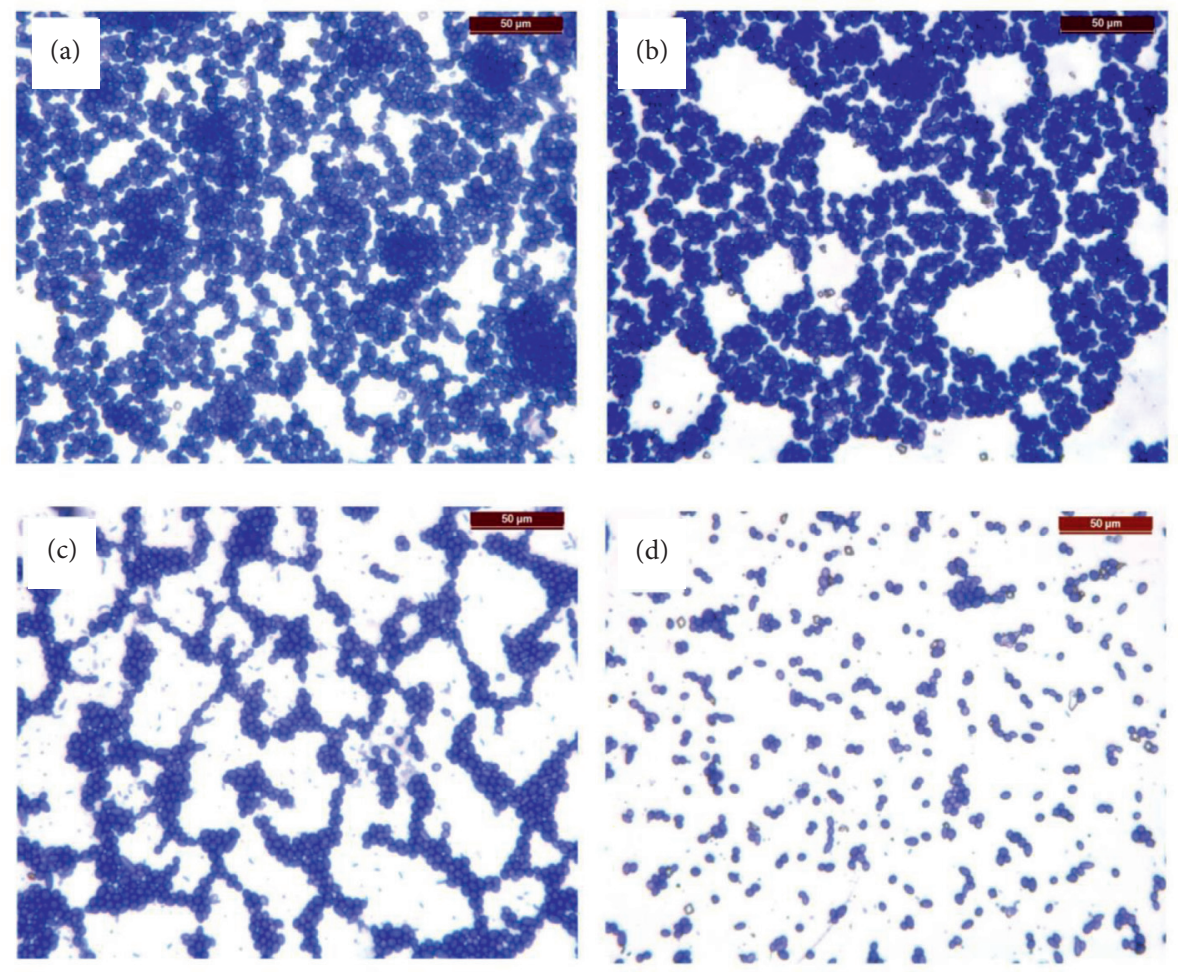

FIgURE 3: Light microscopic images for the antibiofilm activity of AgNPs against C. albicans biofilm. (a) C. albicans biofilm control. (b-d) Biofilm formed in the presence of $0.25 \mu \mathrm{g} \mathrm{mL}^{-1}, 0.5 \mu \mathrm{g} \mathrm{mL}^{-1}$, and $1 \mu \mathrm{g} \mathrm{mL} L^{-1}$ of AgNPs showing dose-dependent reduction of biofilm with different concentrations of AgNPs.

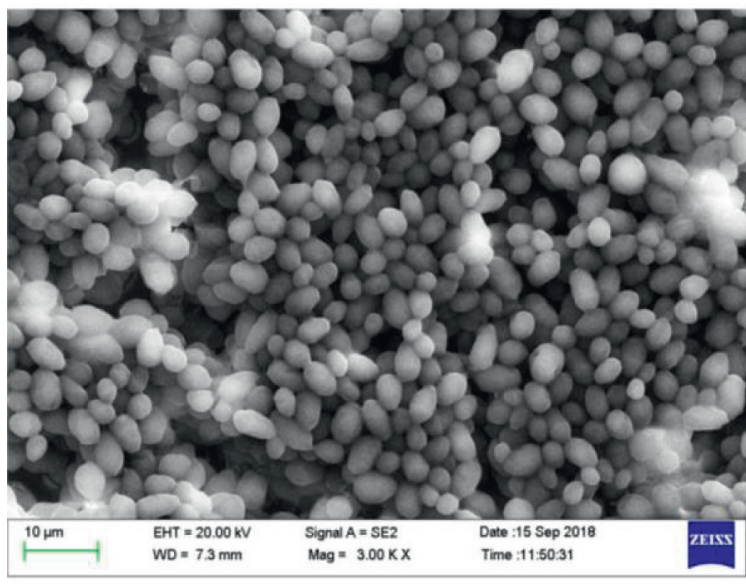

(a)

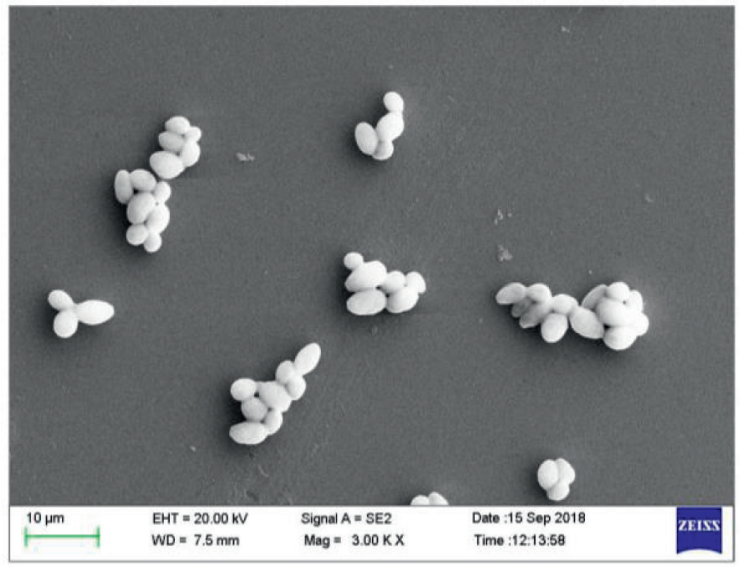

(b)

FIGURE 4: SEM images showing the structure of C. albicans biofilm in the presence and absence of silver nanoparticles. (a) Control. (b) The biofilm treated with $0.5 \mu \mathrm{g} \mathrm{mL}^{-1}$ silver nanoparticles.

colonization and pathogenesis [32]. From the light and SEM images, it was clear that AgNPs significantly reduced the adhesion of yeast cells which has typically proven that hyphal production was also remarkably inhibited and prevented the colonization and pathogenesis of C. albicans. Molecular investigation of aqueous leaf extract of Polyalthia longifolia has shown inhibition of Ras-mediated signal transduction, which includes activation of cascade of genes such as Elongation gene (ECE1), hyphal transition genes
(Tup1 and Rfg1), and hyphal inducer gene (Tec) [33]. Interestingly, chitosan nanofibrous mats used for wound dressing loaded with silver nanoparticles have shown to possess significant antimicrobial and antioxidant property [34]. Thus, from the present study, it is envisaged that AgNPs of $N$. arbor-tristis might have adapted similar mechanism for inhibition of yeast cell adhesion and yeast to hypal switching. 


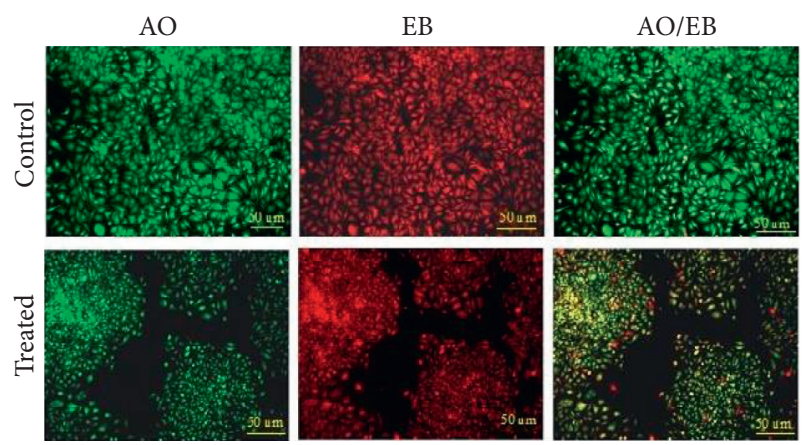

(a)

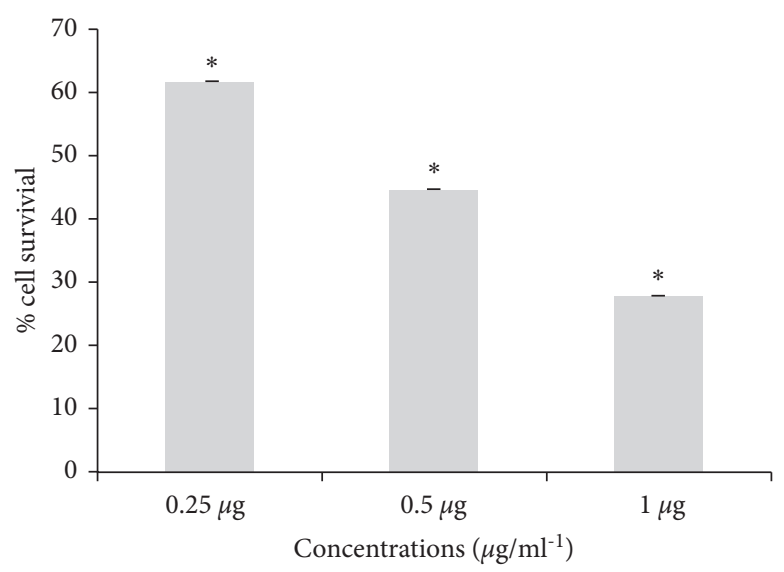

(b)

Figure 5: (a) AO/EB staining showed the morphological changes of HeLa cells visualized under a fluorescent microscope. The cytotoxic effect of AgNPs showed apoptotic cell death. The green circle represents the live cells, the red circle represents the necrotic cells, and the blue circle represents the apoptotic cells. (b) Viability of HeLa cells was examined on exposure to AgNPs after $24 \mathrm{~h}$ incubation. The cytotoxicity was determined by an MTT assay. Data are expressed as the percentage of inhibition compared with a negative control in which cell survival was assumed to be $100 \%$. Statistically significant was indicated as " $*$ " with $P<0.05$.

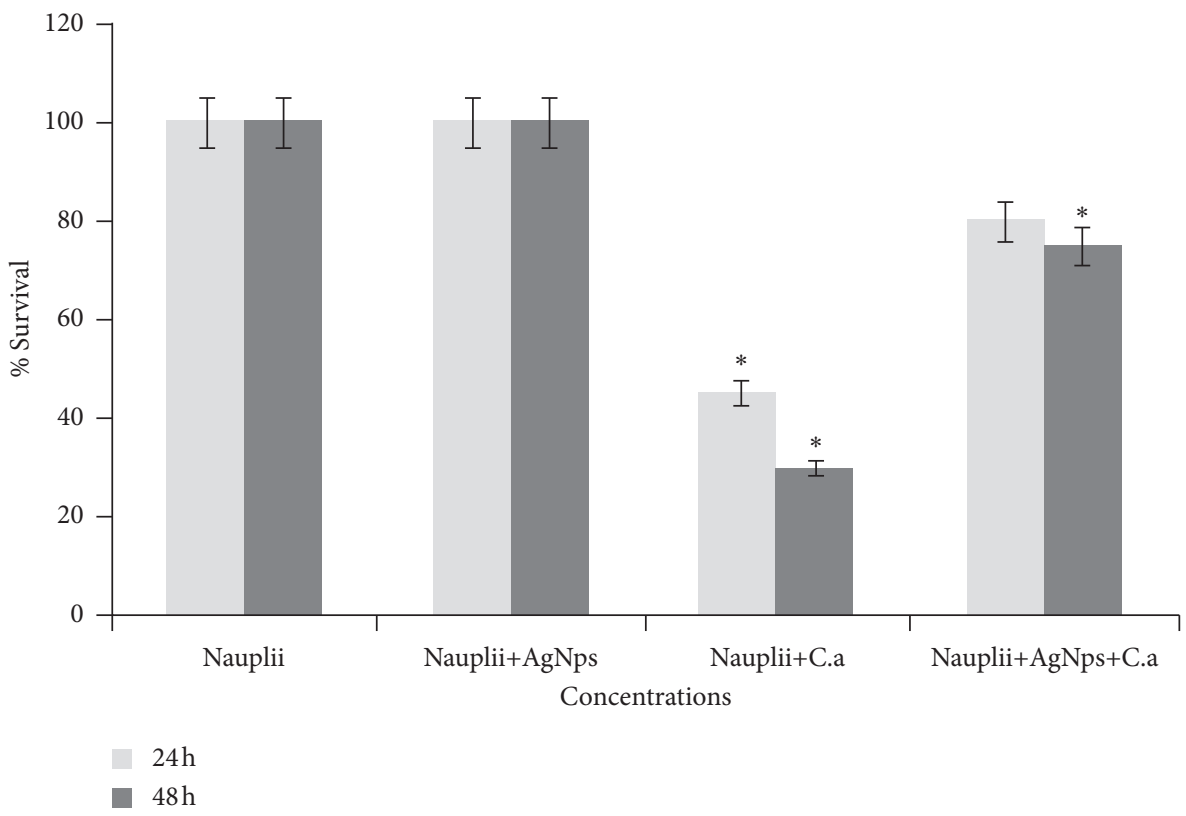

Figure 6: The in vivo effect of AgNPs $\left(0.5 \mu \mathrm{g} \mathrm{mL} \mathrm{L}^{-1}\right)$ on C. albicans-infected brine shrimp at their nauplii stage showing $45 \%$ survival at $24 \mathrm{~h}$ and $30 \%$ survival at $48 \mathrm{~h}$. In the presence of AgNPs, the survival rate of nauplii infected with C.albicans was $80 \%$ at $24 \mathrm{~h}$ and $75 \%$ at $48 \mathrm{~h}$. ${ }^{*} P<0.05$ was indicated as statistically significant.

Later, AgNPs investigated against HeLa cells showed cytotoxic effect as wells morphological changes, which represented the apoptotic cell death. Apoptosis occurs with the decrease in the antioxidant level. The primary role of anticancer drugs is to trigger apoptosis in cancer cells, which was very clear from Figure 5(b), showing cytomorphological changes in the presence of AgNPs. Various reports have also shown that silver nanoparticles from different plant extracts have anticancer activity against human cells $[24,30]$. AgNPs synthesized using Ficus religiosa leaves have shown similar effect on HeLa cells with the shrinkage cells due to rounding of the nuclei [35]. Therefore, the present study also supports the anticancer property of the synthesized AgNPs from $N$. arbor-tristis leaf extract.

The toxic effect of AgNPs on C. albicans infections was tested using Artemia at different periods. Due to various ease features like the hatching of the cyst, short life span, and high vulnerability to toxin, brine shrimp has been a suitable model organism for in vivo experimental studies [36-38]. AgNPs tested against this model organism are nontoxic and significantly able to inhibit the C. albicans. Therefore, AgNPs have been suggested as an antibiofilm agent that can be used 
against C. albicans. However, several studies were focused on the identification of active ingredients such as plant compounds, nanoparticles, and antimicrobial peptides with multiple roles for multitargeting approach. Garlic clove extract-coated silver nanoparticles have shown several roles as antibacterial, antibiofilm, antihelminthic, anticancer, and anti-inflammatory activity [39]. Similarly, catechin overlaid graphene oxide and zinc oxide nanocomposites were reported to have anticancer and antibiofilm activity [40]. Recently, histone H2A-derived antimicrobial peptide has shown potential effect as antibacterial, anticancer, and antibiofilm agent [41]. Thus, from the present study, medicinal plant (N. arbor-tristis) extracts fabricated as AgNPs are reported to have antibiofilm and anticancer effect. In general, immunocompromised and cancer patients are at high incidence of bacterial and fungal infection [42]. Therefore, it is envisaged that identification of nanomaterials with multiple biological potential will surely pave a way to target multiple diseases in the field of biomedical application employed either as coating device or as therapeutic targets at controlled sites.

\section{Conclusion}

In this study, the leaf extract from the medicinal plant (N. arbor-tristis) was used for fabrication, which is costeffective and eco-friendly. The biosynthesized AgNPs showed potential antibiofilm activity against C. albicans. Additionally, AgNPs have also shown cytotoxic effects against HeLa cells. C. albicans, a nosocomial fungal pathogen, affects immunocompromised patients and prolonged hospitalized patients. C. albicans being opportunistic with the disturbance in their environment can cause infection by forming biofilm. Thus, biofilm eradication is most critical since patients do not respond to gold standard antibiotics used for treatment. In recent trends, using nanomaterialcoated devices has been considered as a novel strategy to eradicate the biofilm-related infection. Thus, the present work supports the fabrication of medicinal shrub into AgNPs with dual role as antibiofilm and anticancer agent with least toxicity which can facilitate the usage of AgNPs further as coating material for medical devices and prevent fungal biofilm mediated infections.

\section{Data Availability}

Sufficient data have been included in the manuscript. Additional data can be kindly requested from the corresponding author.

\section{Conflicts of Interest}

All authors declare that they have no conflicts of interest.

\section{Acknowledgments}

Infrastructure facilities provided by the Centre for Nanoscience and Nanotechnology, Sathyabama Institute of Science and Technology and Bharath Institute of Higher Education and Research to carry out this research were acknowledged. Also, student fellowship (JRF) from Department of Science and Technology, India, and This project was supported by Researchers Supporting Project number (RSP-2021/385), King Saud University, Riyadh, Saudi Arabia.

\section{Supplementary Materials}

Figurer S1: EDX analysis and a peak at $3 \mathrm{KeV}$ represents the silver ions as the main component, indicating the fabrication of N. arbor-tristis leaf extract into AgNPs. (Supplementary Materials)

\section{References}

[1] J. S. Finkel and A. P. Mitchell, "Genetic control of Candida albicans biofilm development," Nature Reviews Microbiology, vol. 9, no. 2, pp. 109-118, 2011.

[2] J. V. Desai and A. P. Mitchell, "Candida albicans biofilm development and its genetic control," Microbiol. Spectr, vol. 3, no. 3, 2015.

[3] C. Tsui, E. F. Kong, and M. A. Jabra-Rizk, "Pathogenesis ofCandida albicansbiofilm," Pathogens and disease, vol. 74, no. 4, 2016.

[4] L. Mathé and P. Van Dijck, "Recent insights into Candida albicans biofilm resistance mechanisms," Current Genetics, vol. 59, no. 4, pp. 251-264, 2013.

[5] H. T. Taff, K. F. Mitchell, J. A. Edward, and D. R. Andes, "Mechanisms of Candida biofilm drug resistance," Future Microbiology, vol. 8, no. 10, pp. 1325-1337, 2013.

[6] C. G. Pierce, A. Srinivasan, P. Uppuluri, A. K. Ramasubramanian, and J. L. López-Ribot, "Antifungal therapy with an emphasis on biofilms," Current Opinion in Pharmacology, vol. 13, no. 5, pp. 726-730, 2013.

[7] M. A. Gatoo, S. Naseem, M. Y. Arfat, A. M. Dar, K. Qasim, and S. Zubair, "Physicochemical properties of nanomaterials: implication in associated toxic manifestations," BioMed Research International, vol. 2014, Article ID 498420, 8 pages, 2014.

[8] X. F. Zhang, Z. G. Liu, W. Shen, and S. Gurunathan, "Evaluation of housekeeping genes for quantitative real-time PCR analysis of Bradysia odoriphaga (Diptera: sciaridae)," International Journal of Molecular Sciences, vol. 17, p. 1034, 2016.

[9] T. Yasui, N. Kaji, and Y. Baba, "Nanobiodevices for biomolecule analysis and imaging," Annual Review of Analytical Chemistry, vol. 6, no. 1, pp. 83-96, 2013.

[10] D. Cruz, P. L. Falé, A. Mourato, P. D. Vaz, M. Luisa Serralheiro, and A. R. L. Lino, "Preparation and physicochemical characterization of Ag nanoparticles biosynthesized by Lippia citriodora (Lemon Verbena)," Colloids and Surfaces B: Biointerfaces, vol. 81, no. 1, pp. 67-73, 2010.

[11] K. Arunachalam, S. Annamalai, and S. Shanmugasundaram Hari, "One-step green synthesis and characterization of leaf extract-mediated biocompatible silver and gold nanoparticles from Memecylon umbellatum Memecylon umbellatum," International journal of nanomedicine, vol. 8, pp. 1307-1315, 2013.

[12] S. Jain and M. S. Mehata, "Medicinal plant leaf extract and pure flavonoid mediated green synthesis of silver nanoparticles and their enhanced antibacterial property," Scientific Reports, vol. 7, pp. 1-13, 2017. 
[13] R. Vijayan, S. Joseph, and B. Mathew, "Indigofera tinctoria leaf extract mediated green synthesis of silver and gold nanoparticles and assessment of their anticancer, antimicrobial, antioxidant and catalytic properties," Artificial cells, nanomedicine, and biotechnology, vol. 46, no. 4, pp. 861-871, 2018.

[14] B. M. Abdallah and E. M. Ali, "Green synthesis of silver nanoparticles using the Lotus lalambensis aqueous leaf extract and their anti-candidal activity against oral candidiasis," ACS Omega, vol. 6, no. 12, pp. 8151-8162, 2021.

[15] J. Agrawal and A. Pal, "Nyctanthes arbor-tristis Linn-A critical ethnopharmacological review," Journal of Ethnopharmacology, vol. 146, no. 3, pp. 645-658, 2013.

[16] C. S. Godse, P. S. Tathed, S. S. Talwalkar et al., "Antiparasitic and disease-modifying activity of Nyctanthes arbor-tristis Linn. in malaria: an exploratory clinical study," Journal of Ayurveda and Integrative Medicine, vol. 7, no. 4, pp. 238-248, 2016.

[17] B. B. Kakoti, P. Pradhan, S. Borah, K. Mahato, and M. Kumar, "Analgesic and anti-inflammatory activities of the methanolic stem bark extract of Nyctanthes arbor-tristis linn," BioMed Research International, vol. 8, pp. 62-95, 2013.

[18] T. Sana, B. S. Siddiqui, S. Shahzad et al., "Antiproliferative activity and characterization of metabolites of Aspergillus nidulans: an endophytic fungus from Nyctanthes arbor-tristis Linn. against three human cancer cell lines," Medicinal Chemistry, vol. 15, no. 4, pp. 352-359, 2019.

[19] A. Kumar and H. Kaur, "Sprayed in-situ synthesis of polyvinyl alcohol/chitosan loaded silver nanocomposite hydrogel for improved antibacterial effects," International Journal of Biological Macromolecules, vol. 145, pp. 950-964, 2020.

[20] R. M. Shafreen, B. S. Raja Mohamed, S. Muthamil, M Subramanian, S. K Pandian, and K. P Shunmugiah, "Inhibition of Candida albicans virulence factors by novel levofloxacin derivatives," Applied Microbiology and Biotechnology, vol. 98, pp. 6775-6785, 2014.

[21] I. Koyuncu, A. Gonel, M. Durgun, A. Kocyigit, O. Yuksekdag, and C. T. Supuran, "Assessment of the antiproliferative and apoptotic roles of sulfonamide carbonic anhydrase IX inhibitors in HeLa cancer cell line," Journal of Enzyme Inhibition and Medicinal Chemistry, vol. 34, no. 1, pp. 75-86, 2019.

[22] B. N. Karan, T. K. Maity, B. C. Pal, T. Singha, and S. Jana, "Betulinic Acid, the first lupane-type triterpenoid isolated via bioactivity-guided fractionation, and identified by spectroscopic analysis from leaves of Nyctanthes arbor-tristis: its potential biological activities in vitro assays," Natural Product Research, vol. 33, no. 22, pp. 3287-3292, 2019.

[23] T. Agarwal, S.-A. Tan, V. Onesto et al., "Engineered herbal scaffolds for tissue repair and regeneration: recent trends and technologies," Biomedical Engineering Advances, vol. 2, Article ID 100015, 2021.

[24] S. S. Pallavi, H. A. Rudayni, A. Bepari, S. K. Niazi, and S. Nayaka, "Green synthesis of Silver nanoparticles using Streptomyces hirsutus strain SNPGA-8 and their characterization, antimicrobial activity, and anticancer activity against human lung carcinoma cell line A549," Saudi Journal of Biological Sciences, vol. 29, no. 1, pp. 228-238, 2022.

[25] H. Rawat, Y. Verma, N. S. Ayesha et al., "Nyctanthes arbortristis: a traditional herbal plant with miraculous potential in medicine," International Journal of botany Studies, vol. 6, pp. 427-440, 2021.

[26] T. Kathiraven, A. Sundaramanickam, N. Shanmugam, and T. Balasubramanian, "Green synthesis of silver nanoparticles using marine algae Caulerpa racemosa and their antibacterial activity against some human pathogens," Applied Nanoscience, vol. 5, no. 4, pp. 499-504, 2015.

[27] M. Behravan, A. Hossein Panahi, A. Naghizadeh, M. Ziaee, R. Mahdavi, and A. Mirzapour, "Facile green synthesis of silver nanoparticles using Berberis vulgaris leaf and root aqueous extract and its antibacterial activity," International Journal of Biological Macromolecules, vol. 124, pp. 148-154, 2015.

[28] M. Amin, F. Anwar, M. R. S. A. Janjua, M. A. Iqbal, and U. Rashid, "Green synthesis of silver nanoparticles through reduction with Solanum xanthocarpum L. berry extract: characterization, antimicrobial and urease inhibitory activities against Helicobacter pylori," International Journal of Molecular Sciences, vol. 13, no. 8, pp. 9923-9941, 2012.

[29] V. R. Netala, V. S. Kotakadi, V. Nagam, P. Bobbu, S. B. Ghosh, and V. Tartt, "First report of biomimetic synthesis of silver nanoparticles using aqueous callus extract of Centella asiatica and their antimicrobial activity," Applied Nanoscience, vol. 5, pp. 801-807, 2012.

[30] M. Gulati and C. J. Nobile, "Candida albicans biofilms: development, regulation, and molecular mechanisms," Microbes and Infection, vol. 18, no. 5, pp. 310-321, 2016.

[31] J. B. Kaplan, "Biofilm dispersal: mechanisms, clinical implications, and potential therapeutic uses," Journal of Dental Research, vol. 89, no. 3, pp. 205-218, 2010.

[32] S. D. Halbandge, A. K. Jadhav, P. M. Jangid, A. V. Shelar, R. H. Patil, and S. M. Karuppayil, "Molecular targets of biofabricated silver nanoparticles in Candida albicans," Journal of Antibiotics, vol. 72, no. 8, pp. 640-644, 2019.

[33] M. Bagheri, M. Validi, A. Gholipour, P. Makvandi, and E. Sharifi, "Chitosan nanofiber biocomposites for potential wound healing applications: antioxidant activity with synergic antibacterial effect," Bioengineering and Translational Research, vol. 21, p. e10254, 2021.

[34] B. Modrzewska and P. Kurnatowski, "Adherence of Candida sp. to host tissues and cells as one of its pathogenicity features," Annals of parasitology, vol. 61, no. 1, pp. 3-9, 2015.

[35] J. R. Nakkala, R. Mata, and S. R. Sadras, "Green synthesized nano silver: synthesis, physicochemical profiling, antibacterial, anticancer activities and biological in vivo toxicity," Journal of Colloid and Interface Science, vol. 499, pp. 33-45, 2017.

[36] K. Vasanth, K. Ilango, R. MohanKumar, A. Agrawal, and G. P. Dubey, "Anticancer activity of Moringa oleifera mediated silver nanoparticles on human cervical carcinoma cells by apoptosis induction," Colloids and Surfaces B: Biointerfaces, vol. 117, pp. 354-359, 2014.

[37] G. M. Gajardo and J. A. Beardmore, "The brine shrimp Artemia: adapted to critical life conditions," Frontiers in Physiology, vol. 3, p. 185, 2012.

[38] A. Kumar, T. Behl, and S. Chadha, "Synthesis of physically crosslinked PVA/Chitosan loaded silver nanoparticles hydrogels with tunable mechanical properties and antibacterial effects," International Journal of Biological Macromolecules, vol. 149, pp. 1262-1274, 2020.

[39] A. Kumar and M. Jaiswal, "Design and in vitro investigation of nanocomposite hydrogel based in situ spray dressing for chronic wounds and synthesis of silver nanoparticles using green chemistry," Journal of Applied Polymer Science, vol. 133, no. 14, 2016.

[40] S. Vijayakumar, B. Malaikozhundan, K. Saravanakumar, E. F. Durán-Lara, M.-H. Wang, and B. Vaseeharan, "Garlic clove extract assisted silver nanoparticle - antibacterial, antibiofilm, antihelminthic, anti-inflammatory, anticancer 
and ecotoxicity assessment," Journal of Photochemistry and Photobiology B: Biology, vol. 198, Article ID 111558, 2019.

[41] N. Prakashkumar, R. M. Asik, T. Kavitha, G. Archunan, and N. Suganthy, "Unveiling the anticancer and antibiofilm potential of catechin overlaid reduced graphene oxide/zinc oxide nanocomposites," Journal of Cluster Science, 2021.

[42] P. P. Athira, M. V. Anju, V. V. Anooja, K. Archana, S. Neelima, and P. Rosamma, "A histone H2A-derived antimicrobial peptide, Hipposin from mangrove whip ray, Himantura walga: molecular and functional characterisation," 3 Biotech, vol. 10, no. 11, 2020. 